\title{
13. An analysis of performance management in the South African Department of Labour Robert Cameron
}

\subsection{INTRODUCTION}

After the African National Congress (ANC) was elected to power in South Africa it introduced a swathe of New Public Management (NPM) public sector reforms in the late 1990s. The most prominent of these was performance management. Greater powers were delegated to managers who needed to be held accountable through performance standards. Explicit standards and measures of performance reflecting government priorities had to be defined and performance targets had to be met. This chapter examines labour administration in South Africa primarily through this lens of performance management.

Why did the left-wing ANC government adopt what was regarded as neo-liberal management reforms? The former Minister of Public Service \& Administration, Geraldine Fraser-Moleketi, stated that the reforms were not influenced by NPM ideology. Rather, the government wanted to borrow NPM skills and techniques to modernise the public service without buying into its ideological framework (Cameron, 2009).

South Africa's apartheid labour legislation for the most part relegated black workers to a poor existence with limited rights. After the ANC was elected to power in 1994 it set out to remedy this situation. The Labour Relations Act of 1995 fundamentally changed the landscape. It put in place a progressive piece of legislation, applying to both the public and private sector, ${ }^{1}$ which enhanced workers' rights. The Department of Labour (DoL) was given the responsibility of formulating and enforcing labour legislation.

The chapter briefly contextualises developments in terms of broader changes in public administration, political governance and the economy and then looks at the capacity of the Inspection Enforcement Services (IES) branch to enforce labour relations legislation. It focuses specifically on identifying the problems and obstacles in implementing the DoL performance manage- 
ment system. ${ }^{2}$ The following topics are examined in this regard: Planning and Data; Performance Management policy and procedures, Coordination and Information and Communication Technology (ICT). The chapter draws on reports that the author wrote for the International Labour Organization (ILO) examining the labour administration function in the DoL (ILO 2011; Cameron, 2015). Further research was undertaken in 2018/19 to update the information on the performance of the Department. The methodology for the reports comprised a perusal of recent DoL legislation and relevant documentation, interviews with DoL officials, mainly in the IES branch, and a perusal of secondary literature including ILO documentation, journal articles, book chapters and news articles.

\subsection{PERFORMANCE MANAGEMENT AND NEW PUBLIC MANAGEMENT}

The traditional Weberian model of Public Administration (TPA) has been criticised for hierarchy, red tape and focusing more on structures and processes than outputs. In the 1980s, this model was challenged, initially in Anglophone countries such as England, Australia and New Zealand. The response was NPM, which introduced to the public sector private management concepts, such as performance measurement, downsizing and greater autonomy for managers. NPM was seen as a way of cutting through the red tape and rigidity associated with TPA and redirecting attention to results in the form of more efficient service delivery (Hood, 1991; Pollitt, 1993; Hughes, 2003; Pollitt and Bouckaert, 2011).

A major component of NPM is performance management. If managers are to be given greater autonomy, they need to be held accountable through performance standards (Minogue, 1998: 26). Hood (1991: 4-5) points out that explicit standard measures of performance require that goals are defined, and performance targets are met. This can take the form of using performance indicators and setting targets. Managers should be given more autonomy while being made accountable for performance through a system of rewards and sanctions. It follows that NPM also involves shifting from a focus on inputs to a focus on outcomes or outputs (Hughes, 2003: 54-5; Pollitt and Bouckaert, 2011).

While performance management has in some cases led to improved service delivery, its efficacy has been questioned even in developed countries. Talbot (2005) points out that many aspects of public services are difficult to quantify and this along with the consequences of the rewards and sanctions, may result in changes in behaviour in which performance is not prioritised. He draws on Lindblom, who showed that public decisions are dominated by politics which 
often leads to instability, incrementalism, messy compromises and value judgements which undermine attempts at rational performance measurement.

Hood (2007: 100) argues that gaming, viz. manipulating targets, is widespread in British government. He also states that performance management can lead to a focus on narrow outcomes or outputs for one agency to the detriment of other wider policy and programme objectives. Bird et al. (2005) points out that focusing on indicators rather than the service can result in a type of statistical gaming so that either individuals are excluded from receiving the service whose attendance would be likely to compromise indicators or an institution's range of services is limited in future to those associated with high past performance on measured indicators. Christensen and Lægreid (2015) argue that when managers concentrate on specific outputs, they often tend to ignore outcomes and to stress efficiency rather than effectiveness.

NPM reforms have spread through many developing countries, including much of Anglophone Africa (Schick, 1988; Manning, 2001; Hughes, 2003). The suitability of NPM reforms such as performance management for developing countries is, however, a matter of debate. Schick (1988) argues that developing countries are characterised by informality rather than by formal bureaucratic rules and contracts. He believes that developing countries need old-style Public Administration with a framework of rules and a culture of implementing them before NPM reforms can be introduced (see Larbi, 1999; McCourt, 2013). Pritchett et al. (2012) have a somewhat different interpretation pointing out that the Weberian ideal is not inherently the gold standard to which everyone should aspire. They claim that a variety of organisational forms can lead to similar institutional performance levels, while identical organisational forms can contribute to different performance levels.

Larbi (1999: 26-7), in a review of performance contracting in developing countries, suggests that its successful implementation requires certain preconditions. Capacity issues range from managers' autonomy through to effective management information systems and a well-staffed and well-equipped monitoring agency. These factors are not always present in developing countries. Manning (2001), for example, found the impact of NPM in developing countries to be modest. What was lacking was predictable resourcing, credible regulation of staff, credible policy and customer focus. NPM was driven by angry consumers in developed countries. In developing countries public expectations are low with the result that citizens are likely to think that it is not worth the effort to complain. Talbot (2004: 312-13), in a review of performance management in Jamaica, found a tendency to adopt a 'scatter gun' approach, measuring everything and anything that comes into view. Many of the indicators were operational rather than strategic and were translated into vague and imprecise policy indicators. McCourt (2013: 2) concludes that context is more important than international best practice, which cannot be transplanted uncrit- 
ically from one environment to another. There is a general recognition that one should move away from one-size fits all NPM reforms in developing countries (McCourt and Gulrajani, 2010; Brinkerhoff and Brinkerhoff, 2015). Polidano (1999: 13) argues that reforms intended to introduce results-oriented management in Africa turn out to be long on rhetoric and short on results. Olowu (2010) highlights the poor record of pay and performance reforms in Africa.

\subsection{DEPARTMENT OF LABOUR OVERVIEW}

The Mandela miracle has gone sour in South Africa. There are massive and sustained challenges of low growth poverty, inequality, unemployment and low pay across the economy. The official unemployment rate was 27.5 per cent in September 2018 although unofficially it was over 40 per cent. Debt as a percentage of Gross Domestic Product rose to 56.7 per cent in 2018/19 (DoL, 2019: 2-4). Within the context of a weakening economy and job retrenchments, there has been increased industrial action in South Africa. Recent years have witnessed a few strikes of long duration as well as strikes marked by violence, intimidation of non-striking workers, damage to property and deaths.

The South African Constitution of 1996 makes provision for a three-sphere system of government, namely national, provincial and local. Labour administration is entirely a national government function. The national department has nine provincial offices along with 126 Labour Centres which together implement labour policy. The national office is the policy-making body. Provincial offices provide technical and administrative support to local Labour Centres through their business units. In 2019, the Department had a staff complement of 2,206 . Services are also rendered at 40 satellite offices and 492 visiting points across the country. DoL uses a fleet of fully equipped mobile buses to provide services at satellite and visiting points (DoL, 2018a: 4-5; 2019: 6). The Labour Centres were established under the provisions of the Skills Development Act of 1998. They are responsible for providing employment services for workers, employers and training providers to help promote employment, income generating projects, and education and training programmes (ILO, 2010: 5-6). This organisational structure is based on a decentralised NPM corporatist model (Hood, 1991).

The DoL has three main branches: Inspection and Enforcement (IES); Public Employment Services (PES); and Labour Policy and Industrial Relation (LP\&IR). The IES branch aims to ensure a fair and equitable labour market 
where all players adhere to the provisions of legislation that governs the labour market. The main functions of the inspectorate are:

- To examine how national labour standards are applied in the workplace through inspection and enforcement of labour legislation and to educate and advise social partners on labour market policies.

- To conduct workplace inspections and audits of Accredited Inspection Authorities to monitor and enforce compliance with labour legislation.

- To provide advice, educate and give technical information and support services to empower both workers, employers and stakeholders and to prevent labour disputes and workplace accidents.

- To investigate workplace health and safety incidents once reported (DoL, 2017: 4).

The DoL aims to ensure that employers adhere to decent work principles and ensure that vulnerable workers are protected. Over the medium term, the Department plans to enhance enforcement by increasing the number of inspections for compliance with labour legislation (DoL: 2019: 5). However, as will be pointed out, there are a number of constraints.

\subsection{DEPARTMENT OF LABOUR LEGISLATION}

A number of DoL Acts were amended in the 2010s in order to align legislation with the ILO standards and conform with the government's development vision, the National Development Plan (National Planning Commission, 2012), which identified apparent rigidities in the labour market and called for a modernisation of industrial relations.

There is some legislation which does not impact on IES directly and it will be briefly mentioned. The Labour Relations Amendment Act of 2014 gives greater protection to informal employees and the Employment Services Act of 2014 aims to strengthen the provision of employment services within the DoL. The National Minimum Wage Act of 2018 provides for, amongst other things, a national minimum wage, the establishment of a National Minimum Wage Commission, a review and annual adjustment of the national minimum wage, and the provision of exemptions from paying the national minimum wage. The legislation took effect on 1 January 2019 (DoL, 2019: 4). Enforcement of the national minimum wage is the responsibility of IES.

The Basic Conditions of Employment Amendment Act of 2013 impacts on IES directly. It aims inter alia to address the government's commitment to avoid exploitation of workers, to ensure 'decent' work for all workers, to introduce laws to regulate contract work and to strengthen the implementation and enforcement mechanisms of the Act, for example, increased fines 
for non-compliance. This legislation places extra responsibilities on Labour Inspectors. In addition to tougher enforcement and implementation, they must also notify employees of their rights and responsibilities.

The Occupational Health and Safety (OHA) Act of 1993 is the only piece of legislation that falls under the purview of the IES branch. The DoL is (in 2020) in the process of amending the legislation but this has not happened yet as the Bill has become mired in the legislative process. The DoL argues that although the OHS Act has placed responsibility for creating a healthy and safe working environment on the employers, the provisions compelling employers to take steps in this regard are very vague. The Act needs to be amended in order to ensure that employers develop and implement a health and safety management system and penalties issued to non-compliant employers must be increased (DoL, 2015a: 4). What is of importance is that the enforcement provisions will be revised and strengthened, the administrative system for issuing fines will be simplified, and the inspector will be empowered to issue administrative fines on the spot. Penalties will be substantially increased (DoL, 2018a: 5-6; Beware Changes to the OHS Act, SHEQ Management, 2018).

The original OHS Act was promulgated in 1993. Unions have objected to the longevity of this legislation because it is seen as a legacy of the apartheid era. Notwithstanding this, the Act was in line with the then ILO guidelines. The legislation now needs updating. The first problem is the tortuous process of ensuring that health and safety is complied with. One interviewee gave an example of the unsatisfactory process, as follows: A Labour Inspector issues a piece of paper in the form of a prohibition notice to a builder, for example, incorrect scaffolding. The builder can appeal against it and it takes 6-12 months to get to court, and by this time the project has been completed using incorrect scaffolding.

A second problem is that the courts do not treat labour issues (including deaths) with the same seriousness as murder and rape. The National Prosecuting Authority (NPA) is generally reluctant to take workplace fatalities cases to court and the DoL is therefore trying to convince the NPA of the seriousness of such contraventions. The intention is both to speed up the process and to give Labour Inspectors more powers.

A third problem is that the fines have not been increased since 1993 and are extremely low. A R10,000 (approximately 600 USD in 2020) fine on a project of R200 million is negligible and is not a disincentive to some builders in the construction industry, who would rather pay the fine than deal with the prohibition. The Amendment Bill therefore includes a proposal to increase fines to R100,000.

The Amendment Bill process started in 2010 but encountered a number of obstacles. Firstly, the Bill had to go through a number of hoops - including the Minister's Advisory Council on OHS, the State Law Adviser, and the 
National Economic Development and Labour Council (NEDLAC). ${ }^{3}$ In addition, the Portfolio Committee on Labour was concerned that if a fine of around R100,000 was imposed it would lead to attempted bribery of Labour Inspectors and the Bill was consequentially sent back to the Department (interviews). In May 2018, the Cabinet approved the OHS Amendment Bill of 2018 although it has not yet been made available for public comment. It is not yet known how this contested issue of higher fines has been dealt with nor when the Bill will eventually be made available for public comment.

\subsection{PLANNING AND DATA}

The government has developed 12 key outcomes ${ }^{4}$ to reflect government policy priorities. In the medium term, the DoL is concentrating mainly on the following government outcomes:

4: Decent employment through inclusive economic growth;

5: A skilled and capable workforce to support an inclusive growth path;

11: Create a better South Africa, a better Africa and a better World;

12: An efficient, effective and development oriented public service;

14: Transforming society and uniting the country (DoL, 2018a: 12).

The Ministerial Programme of Action is for five years and is derived from the government outcomes. It discusses the key aims and objectives, assesses achievements and challenges against a set of key targets, and conveys this information to the public and labour market community. The President signs performance agreements with the relevant ministers, who are responsible for developing a delivery agreement that refines and provides more detail on the outputs, targets, indicators and key activities for each outcome, and also identifies required inputs and clarifies roles.

The relationship between the Strategic Planning and Performance Plans is as follows (DoL, 2015b, 2017: 10). The five-year Strategic Plans identify the strategically important goals and objectives against which the DoL's medium-term results can be measured and evaluated by Parliament and the public. In order to achieve the programme objectives determined in the strategic planning process, the Annual Performance Planning (APP) has to identify the performance indicators and targets that the DoL will seek to achieve in the upcoming financial year. The Quarterly Performance Reports (QPR) are the main standards for organisational monitoring in a given financial year. The Annual Performance Reporting (APR) which is the Annual Evaluation will look for 'what is going well' and 'what is not progressing' in terms of intended results. It then records this in resolutions, makes recommendations, and follows up with decisions and action. 
IES staff at the Labour Centres are required to provide monthly reports to Regional Managers in terms of performance goals. Staff have to point out the extent to which targets have been reached and reasons for non-compliance, as well as remedial action to correct the deviances. IES staff in the provinces have to verify the data. It is then sent to the Chief Director: Provincial Operations (CDPO) in the head office. A manager in the IES head office is responsible for consolidating provincial data into national reports.

\subsection{PERFORMANCE MANAGEMENT}

The Public Service Laws Amendment Act of 1997 introduced NPM-type performance management in South Africa. The Public Service Regulations of 1999 gave performance management more flesh by providing more detailed guidelines (Miller, 2005: 86-9).

There are two main official documents that look at organisational performance management. Firstly, the National Treasury (2007) produced a document called Framework for Managing Programme Performance Information. The document asserted that budgets are developed in relation to inputs, activities and outputs, while the aim of management is towards achieving the outcomes and impacts. Secondly, the Presidency (2009) issued a report entitled Improving Government Performance, which looks at ways of improving government's organisational performance. There is now an emphasis on the outcomes performance management system. The starting point of this process is the Medium-Term Strategic Framework (MTSF). It is a five-year plan arising from the government's Vision 2025 and other issue-specific policy research. The MTSF is converted into the main outcome indicators, approved by Cabinet.

The President establishes performance agreements with ministers and in sectoral delivery agreements, focusing on a small set of outcomes and a selected group of outputs. Ministers will cascade results-focused lines of accountability down to senior officials. In the last few years, the monitoring of performance has become the primary responsibility of the Department of Planning, Monitoring and Evaluation (DPME) located in the Presidency.

\subsubsection{Management Performance Assessment Tests}

Management Performance Assessment Tests (MPAT) provided a comparative (one-off) analysis of the 41 National Departments in the 2012/13 financial year. These were conducted by the DPME (2013). The MPAT rated performance according to four levels:

- Level 1 - non-compliance with legal/regulatory requirements 
- Level 2 - partial compliance with legal/regulatory requirements

- Level 3 - full compliance with legal/regulatory requirements

- Level 4 - full compliance, and doing this smartly.

Overall, the DoL received an average of 48 per cent for four indicators (strategic management, governance and accountability, management of human capital and financial management) having achieved levels 3 and 4 performance standards. This put the Department at joint 24th, along with two other departments, out of the 41 national departments surveyed. The Department is therefore just below the mid-way point of the rankings, although it should be noted that the percentage achievements are still relatively low.

\subsubsection{Performance Management in the Department of Labour}

The ILO (2011) found that the introduction of performance management in the DoL had not fulfilled the intentions of policy makers and had not had a significant impact on the behaviour of officials. However, a number of senior officials felt that while performance management had not led to better performance it was the only benchmark for measuring performance and should be improved. In particular, there needed to be a link between the government's programme of actions (i.e. NDP, MTSF, the Departmental Strategic Plan and the APP) and a link between the Departmental Strategic Plan, APP, Branch Work Plans, QPR and Individual Performance Agreements.

In order to ensure that the DoL meets its organisational performance indicators and targets, it must ensure that it measures performance both at organisational and individual levels. Each individual is required to agree performance objectives and targets that are linked to his/her team, Programme and the DoL's APP. Once the Departmental objectives and targets have been set in the APP they must be cascaded down to Branches, Provincial Offices, Labour Centres and all teams and employees of the Department. In the early 2010s, the IES at head office largely set the targets for the provinces. In the last few years there has been much greater interaction between the Chief Directorate and the provinces. The head office can now link up with the incumbents of the newly created Provincial Chief Inspectors (PCIs) posts in order to define the scope of work. They can jointly determine relevant targets and determine what areas Labour Inspectors should be working in. This means that targets can be set at an organisational level, viz. national and provincial government rather than just at national government, viz. branch level. Senior managers interviewed viewed this as a positive step in that provincial offices which had greater awareness of coalface issues and could now be involved in setting targets. However, some interviewees stated that targets were set some time ago and 
are adjusted incrementally on an annual basis. This means that joint setting of targets is confined to a few areas on the margins.

\subsection{PERFORMANCE TARGETS AND DATA}

The ILO $(2010 ; 2011)$ raised concerns about the verification of data in the monthly reports from provinces. Because of the manual case management system (see section on ICTs), provinces find it difficult to provide accurate and detailed information. The other problem is that data are not standardised and different provinces measure targets in different ways. As a result, the head office does not have sufficiently accurate and comparable information about activities across the provinces. According to interviews, the verification of data was taken more seriously in the late 2010s.

For each quarterly performance indicator and target achieved or not achieved, there must be source/supporting documentary evidence for verifying data. There must also be a reason for deviation or variance and for audit purposes, there must be evidence of why the performance indicator and target were not achieved, that is, the variance (DoL, 2015c). Sometimes targets are not met due to variations between data in the quarterly reports although it tends to balance out over the year. At other times targets are not reached due to the Internet system working very slowly. At provincial level, staff members who do not achieve targets are reported for non-performance. This leads to staff manipulating data because of concern about their jobs. Sometimes staff make excuses for non-performance, but these tend to be exceptions.

A number of interviewees claimed that, despite its limitations, the manual case management system had improved since the early 2010s. The DoL has been trying to improve performance, particularly in provinces and Labour Centres. Interviewees said that there had been an improvement in the quality of data that the head office received from provinces, most notably the quarterly reports, although the accuracy of pockets of data could still be questioned. The branch had been using Treasury's Technical Indicator Guidelines which had led to this improvement. The Deputy Director-General: Chief Operations Officer (DDG: COO) said that 85 per cent of files had been verified. Other interviewees said that although the manual system had improved (it had become quicker), one had to send emails and phone calls to obtain information. Other interviewees said that the manual system was still too cumbersome in that it took too long to process information when requested. It was also suggested that it depended on the person concerned as to whether one would be provided with a speedy response (Cameron, 2015; ILO, 2015).

As shown in Table 13.1, in 2018 the IES had reached 50 per cent of its performance indicators. The specific areas of underperformance are shown in Table 13.2. A major problem has been a shortage of Labour Inspectors. 
Table 13.1 Departmental performance per programme

\begin{tabular}{l|c|c|c|c}
\hline Programme & $\begin{array}{c}\text { Performance } \\
\text { Indicators }\end{array}$ & Achieved & Not Achieved & $\begin{array}{c}\text { Overall } \\
\text { Achievement }\end{array}$ \\
\hline Administration & 4 & 3 & 1 & $75 \%$ \\
\hline IES & 4 & 2 & 2 & $50 \%$ \\
\hline PES & 4 & 4 & 0 & $100 \%$ \\
\hline LPIR & 8 & 3 & 5 & $38 \%$ \\
\hline Total & 20 & 12 & $80 \%$ & \\
\hline $\begin{array}{l}\text { Overall } \\
\text { performance }\end{array}$ & & $60 \%$ & & \\
\hline
\end{tabular}

Source: DoL (2018b: 43).

The Department has faced challenges in both retaining inspectors and finding suitable, specialised candidates. The R64 million allocated for an additional 124 Labour Inspectors in 2016/17 was withdrawn, implying that it would no longer be possible to add inspectors or fill some of the vacancies, thereby seriously hampering the ability to increase the number of inspections from 2014/15 to 2019/20 by 30 per cent as required in the MTSF (DoL, 2017: 8). The branch was due to receive 500 new Labour Inspector posts in 2019, but this decision was reversed and large cuts were made to the DoL's Medium Term Expenditure from 2019/20 to 2021/22 as part of the government attempts to cut government debt. R13.5 million of these cuts will come from IES. This is expected to have a huge impact on the Department's daily operations, as the human capacity will be stretched and items such as communication, operating payments and training and staff development had to be cut to accommodate these reductions (DoL, 2019: 27). Furthermore, there is the problem of underqualified staff and inspectors at Labour Centres. The then Labour Minister, Mildred Oliphant, called for the strengthening of institutional capacity through ensuring that necessary infrastructure is in place, the hiring of experienced staff and training of employees. She identified another big challenge facing the Department, 'the inability to enforce compliance' (DoL, Department of Labour meets to take stock of its performance, 19 July 2018). These issues will be examined in more detail in Section 13.10.

\subsection{COORDINATION}

The Department has a well-developed organisational structure to deal with internal coordination of performance. Despite this elaborate system, the DoL structures for horizontal coordination have been less than ideal. A senior IES official said while there had been policy development linkages at strategic 
Table 13.2 IES areas of under-/overperformance

\begin{tabular}{|c|c|c|c|c|}
\hline Key Outputs & $\begin{array}{l}\text { Programme Performance } \\
\text { Indicator }\end{array}$ & $\begin{array}{l}\text { Planned } \\
\text { Target } \\
2017 / 18\end{array}$ & $\begin{array}{l}\text { Actual } \\
\text { Achievements } \\
2017 / 18\end{array}$ & $\begin{array}{l}\text { Deviation and } \\
\text { Comments }\end{array}$ \\
\hline \multirow[t]{4}{*}{$\begin{array}{l}\text { Workers } \\
\text { protected } \\
\text { through the } \\
\text { inspection and } \\
\text { enforcement of } \\
\text { employment } \\
\text { law }\end{array}$} & $\begin{array}{l}\text { 1. Number of employers } \\
\text { inspected per year }\end{array}$ & 217008 & 214946 & $\begin{array}{l}-2062 \\
\text { The } \\
\text { underachievement } \\
\text { was due to the } \\
\text { number of vacant } \\
\text { posts in the branch }\end{array}$ \\
\hline & $\begin{array}{l}\text { 2. Percentage of } \\
\text { non-compliant } \\
\text { employers served } \\
\text { within } 14 \text { days of } \\
\text { inspection }\end{array}$ & $80 \%$ & $100 \%$ & $\begin{array}{l}19.8 \% \\
\text { The Branch } \\
\text { prioritises the } \\
\text { enforcement } \\
\text { of the law for } \\
\text { non-compliant } \\
\text { employers }\end{array}$ \\
\hline & $\begin{array}{l}\text { 3. Percentage of } \\
\text { non-compliant } \\
\text { employers who failed } \\
\text { to comply referred for } \\
\text { prosecution within } 30 \\
\text { calendar days }\end{array}$ & $60 \%$ & $35 \%-$ & $\begin{array}{l}-25 \% \\
\text { The } \\
\text { underachievement } \\
\text { was due to a lack } \\
\text { of capacity and } \\
\text { vacancies in the } \\
\text { branch }\end{array}$ \\
\hline & $\begin{array}{l}\text { 4. Percentage of reported } \\
\text { incidents investigated/ } \\
\text { finalised within pre- } \\
\text { scribed time frames }\end{array}$ & $65 \%$ & $75 \%$ & $\begin{array}{l}10 \% \\
\text { Due to risks } \\
\text { associated } \\
\text { with incidents, } \\
\text { investigations were } \\
\text { prioritised }\end{array}$ \\
\hline
\end{tabular}

Source: DoL (2018b: 49-53).

level, they tended to be operational silos whereby the various branches or even directorates of the same branch do not always coordinate and harmonise the implementation of policy effectively. This has led to disjointed implementation which can affect the quality of services received by the DoL's clientele.

There was another problem with the DoL structure which relates to its NPM corporatised model. Hood (1991: 4-5) refers to corporatisation as the disaggregation of units in the public sector. This involves breaking up central government departments into corporatised units around services, with units dealing with each other on an arm's-length basis. In South Africa, there is a split 
between a small strategic policy core and large operational arms of government which have increased managerial autonomy to promote efficient service delivery. These arm's-length agencies were supposed to provide greater flexibility for management in return for greater accountability for results (see Larbi, 1999). However, the organisational structure worked less than optimally ( DoL, 2011; ILO, 2011). It proved insufficiently flexible to respond to service delivery needs and the fact that three levels were involved - national offices, provincial offices and Labour Centres - resulted in an overly complex, if not cumbersome, division between policy making and implementation arms. This will be discussed below.

The ILO (2011) identified a number of problems relating to reporting lines and coordination. At that time, the DoL's head office set strategy and policy and provided support to provinces and Labour Centres through, for example, briefing sessions with the DDG: COO, regular meetings with the CDPOs, meetings with business unit managers and road-show presentations. Provincial offices of the DoL provided support to Labour Centres, while IES service delivery was performed at Labour Centres headed by regional managers. They were accountable to the CDPOs in the respective provinces, who in turn reported to the DDG: COO at head office. The head office provided leadership and focused on strategic issues. The CDPOs at provincial level were accountable for the operations of the provincial offices and Labour Centres were the coalface of service delivery. If CDPOs did not achieve the targets that were allocated to their respective offices, they did not need to account for this failure. Neither national nor provincial staff were permitted to go directly to the Labour Centres without permission from the CDPO. Both national and provincial IES staff expressed frustration that they did not have a say over the activities of their staff at Labour Centres. The regional managers had autonomy over human resources at Labour Centres. The national directorate was ultimately responsible for achieving national targets but had no direct control over the activities of IES staff at the Labour Centres.

The ILO (2011) recommended that matrix-type relationships be introduced, in which IES staff at Labour Centres would be accountable to their respective provincial counterparts, who in turn would be accountable to the respective national office. The role of the CDPO would then become one of providing management support services, such as the provision of infrastructure and staff. This system would lead to dual lines of accountability. Since 2011, there have been reforms to the system. Provinces are now called Business Units; there has been the introduction of a new post, Provincial Chief Inspectors (PCIs), and there are now Labour Inspector specialists located in provinces. Regional Managers are now called Labour Centre Operations Managers. There has also been an increase in the car fleet for Labour Inspectors (which had previously been identified as a constraint). These changes have led to greater capacity at 
provincial level and improvements in service delivery. These changes have certainly given IES more 'clout' at provincial level than hitherto been the case - the PCI now reports directly to the CDPO.

There are still, however, problems relating to coordination. The matrix system has not yet been implemented and senior managers in IES still have to go through the CDPO in order to get access to the PCI. The PCI reports directly to the CDPO, his/her immediate supervisor, who does his/her performance evaluation. Some senior management interviewees found this system quite frustrating because they were unable to direct a Labour Inspector to go to a site in a time of crisis. A counter argument to this is that if the national office intervenes directly, it can be accused of interfering in operational matters.

\subsection{INFORMATION TECHNOLOGY}

In 2002 the DoL entered into a ground-breaking information and technology partnership deal with Siemens Business Services. This deal, concluded under the aegis of a Public Private Partnership (PPP), was worth (initially) a total of over R1.2 billion over a period of ten years. The aim was to ensure an integrated approach to service delivery; enhance the utilisation of information as a strategic resource and to integrate information technology systems more effectively.

In 2010, the ILO (2010: 31) had recommended that the IES introduce an ICT system for case management, to cover registrations, referrals and document management. The branch had been operating without reliable and efficient technology, which had resulted in unreliable data, poor reports generated, and poor management of cases and feedback to clients. Each province had its own inspection manual and IES performance standards, and a common ICT system was lacking. This inhibited collaboration and the establishment of a national standard which in turn inhibits the creation of uniform and reliable data, which are essential for proper performance management. The DoL's Strategic Plan (2011: 8) indicated that information technology systems are not integrated and, in most cases, do not support service delivery needs. It was also not functioning properly (ILO, 2011; Cameron, 2015).

The PPP contract between DoL and Siemens came to an end on 30 November 2012 and was not renewed by the Department. After the termination of the contract, the Minister of Labour, Mildred Oliphant conceded in Parliament that the DoL failed to ensure its staff members were sufficiently trained and prepared to provide IT services during the ten-year contract with Siemens. IT service provider, EOH Holding was appointed by the DoL as a transitional measure. When EOH's involvement ended in 2015, DoL did not have a functioning electronic case management system. DOL took over 
96 employees from $\mathrm{EOH}$ at the end of its contract. and began providing the service delivery (Cameron, 2015).

A major problem was that the system could not cope with all of the information that it was supposed to include in the database, which in the case of the IES included eight pieces of legislation and voluminous regulations. Interviews revealed that the lack of a functioning electronic case management system had demoralised staff. If an effective electronic case management system was in place, the Head Office could know exactly where Labour Inspectors were - it could help management steer Labour Inspectors to where there was a major problem. As one senior Labour Inspector put it: 'What happens if there is a major disaster after hours, e.g. a local Chernobyl? Management will not be able to get hold of Labour Inspectors.' A functioning electronic case management system would also be more effective for ensuring the provision of feedback to complainants (Cameron, 2015; ILO, 2015).

The manual system made it difficult to reconcile the number of cases that are conducted by Labour Inspectors. This was particularly problematic in the visiting of sites which had no computer facilities at all. Labour Inspectors had to handle each case manually on paper and these had to be reconciled with the relevant files in the Labour Centres. Most provinces still used Excel spreadsheets. This system lent itself to the miscounting of numbers of cases. There are, however, some who continue to defend the manual system. For example, one official claimed that a proper paper trail of documentation was required, like a lawyer's case (which in some instances became legal cases anyway; Cameron, 2015; ILO, 2015). Despite the limitations of the manual system, there are checks and balances to minimise fraud. A case has to be seen by three Labour Inspectors and Management can still access case files (albeit still in a manual format). Furthermore, the case had to be signed off by the complainant. Of the approximately 1,340 Labour Inspectors working in South Africa, only six were implicated in fraud in 2014.

While the manual system continues to exist at the time of writing, there has been an improvement in the implementation of an effective ICT system in the last few years. Prior to 2012 there was no performance indicator for the ICT system. However, a new indicator - 'the Percentage of elements of the ICT strategy implemented in a financial year' - was introduced in 2011/12 (DoL, 2013). The indicator was refined as 'to annually review and implement the ICT strategy of the Department' and audited for the first time in 2012/13. It was found that the Department had met 50 per cent of its targets for 'implementing strategic plan components' (DoL, 2014, 2015a). ICT weaknesses do remain, however, and are continuing to have a negative impact on service delivery, which is heavily dependent on the functionality and reliability of IT systems (DoL, Department of Labour meets to take stock of its performance, 19 July 2018). 


\subsection{EVALUATION OF THE PERFORMANCE MANAGEMENT SYSTEM}

The research found that there are some positive aspects of the DoL's performance management system. It has been extensively developed and is well thought through. There also appear to be some links between operational plans and government's plan of action. Most interviewees felt that the introduction of performance management had not fulfilled the intentions of policy makers. However, there were strong feelings that while performance management has not led to the improvement of services, it is the only benchmark for measuring performance and should be improved. It should also be noted that the performance management system gradually improved across the 2010s.

An evaluation of IES performance will now be undertaken. There are four main categories which are discussed.

\subsubsection{Measurement and Design}

The first category is that of problems of measurement and design. Firstly, the government is attempting to move away from the outputs system to an outcomes-orientated approach. In the interviews, it was ascertained that this was difficult to achieve in practice. A major reason has been resistance from managers who prefer the outputs-based approach, which is more difficult to quantify. One senior IES manager said the Department was stuck in the rut of trying to achieve 'numbers' as opposed to focusing on the services that the branch should be providing.

Secondly, there was the problem of too many indicators. In the early 2010s the DoL had 133 indicators and many of them were operational rather than strategic. This resulted in vague and imprecise policy indicators. In the mid-2010s, the number of indicators was reduced to 48 . They are now more precise and strategic and less operational. In addition, the verification of data has improved and despite its limitations, the operation of the case management system has improved. This has been accelerated by the appointment of the current Director-General (DG), who was an internal nominee with deep knowledge of ministry and issues under its mandate. There also appears to be a greater performance culture in the Department with more vibrancy and expectation that managers deliver and a greater emphasis on managers being held accountable for their actions, with the DG having facilitated several changes at a senior management level.

Finally, there is the link with coordination. The government is emphasising performance that cuts across departments and within them. It is felt that this would help in reaching outcomes rather than outputs. There is teamwork 
amongst the DoL branches. However, there was a feeling that the individually based performance management system is not geared for teamwork, which involves extensive coordination between and within departments (see Pollitt, 2003).

\subsubsection{Gaming and Compliance}

The second category is that of the gaming of the performance management and compliance.

Firstly, there was a strong view amongst the interviewees that the performance management system was inconsistent, subjective and arbitrary, with undeserving people getting rewards and deserving people not. One interviewee said that 'in principle, performance bonuses should be for highfliers although in reality it [is] hijacked by other people'. To what extent this is simply the views of disgruntled staff who failed to qualify for bonuses is, however, a matter of conjecture. Secondly, as pointed out, some officials deliberately kept performance contracts too vague, which enabled staff to reach targets and bonuses more easily. Thirdly, there was a concern raised about managers not making tough decisions in performance ratings. Managers do not want to be unpopular and deal with discontent. This was particularly frustrating to national and provincial IES managers, who have seen non-performing staff getting bonuses at some Labour Centres but have no control over this process. Finally, the DoL has had to change the Strategic Plan and the APP on a few occasions. After the 2014 and 2019 national elections there were new outcomes, and the DoL had to change priorities on its Strategic Plan. This has affected the signing of performance agreements with both ministers and officials. In the case of the signing of performance agreements with ministers, the President announced after the May 2019 elections that members of the Cabinet would sign performance agreements with him (SABC News, 30 May 2019). However, this was delayed until the conclusion of the MTSF. It was argued that it was not possible to enter into performance agreements with ministers, when there was no clarity on what government will do for five years. The MTSF has been completed and the Minister in the Presidency recently announced that performance agreement assessments would take place on a six-monthly basis, twice a year for all ministers and government departments in all nine provinces (SA News, January 2020).

Finally, there has also been a rapid turnover of DGs in the DoL. From 1994 to 2009 there have been five different DGs of which three have been permanent and two have been acting. This has been disruptive administratively. There is now greater continuity. The current DG was appointed in December 2014 and is still in post at the time of writing. This has led to better management and leadership. 


\subsubsection{Lack of Capacity}

The next category is lack of capacity. Firstly, the ICT systems are not integrated and, in most cases, do not support service delivery needs. This inhibits collaboration and the establishment of a national standard, which in turn inhibits the creation of uniform and reliable data, which are essential for proper performance management. The Auditor General's (AG's) 2014 report stated that he could not obtain sufficient evidence that the information provided in the financial statements was accurate and credible. He went on to say that the published annual performance report of the DoL included information (on their performance against predetermined objectives) that was not useful and reliable for the IES. The AG was particularly concerned about the veracity as well as the reliability and usefulness of data. In terms of veracity, the way that performance was set did not comply with the SMART (Specific, Measurable, Achievable, Relevant and Time bound) principle in that it was not measurable. When it came to reliability it was found that there was not sufficient evidence to corroborate the claims about the number of labour inspections that were undertaken, given that the Department was relying too heavily on the manual system. Since then performance management has improved but, as noted, the IT problems persist.

Secondly, the DoL's Strategic Plan (2011: 8) pointed to the weak capacity of the Labour Centres to provide fully fledged and individualised services to workers, job seekers and employers. It was noted that there is a major shortage of skilled Labour Inspectors at Labour Centres. This means that existing staff are overstretched and struggle to meet their targets. New Labour Inspector posts have been promised but have not been forthcoming due to the cutting of budgets.

Finally, the lack of management and leadership skills among some (but not all) regional managers was identified as a problem by interviewees. There was also concern by both national and provincial IES and staff about the quality of some of the staff, who were, in effect, appointed to positions at Labour Centres by regional managers (although they had to be signed off by the CDPOs). There was a sense of frustration by these provincial staff over some of these appointments as the best people were not always appointed to the job. A related problem is that posts have been upgraded, most notably that of the Labour Centre Operations Managers, for example, moving from Assistant Administrative Officer (AOO) rank to Deputy Directors without the commensurate improvement in skills. Staff have been elevated up the hierarchy and, in some cases, have dragged their deficiencies up with them. 


\subsection{CONCLUSION}

DoL legislation has been changed in recent years in order to align labour law with ILO standards and the NDP, which identified alleged rigidities in the South African labour market and called for a modernisation of industrial relations. Legislation has been put in place to improve the efficiency of the labour inspectorate. In addition, extra responsibilities have been given to Labour Inspectors, who are faced with tougher enforcement and implementation expectations.

The DoL has an extremely well-developed performance management system where all members of the Department, including the Minister, have their performance evaluated. The Department has also significantly reduced the number of performance indicators, which have been made more strategic and less operational. The verification of data has improved, and despite its limitations, the operation of the case management system has also improved. The Department has also improved its capacity for internal coordination. However, weaknesses remain, particularly in relation to staff shortages, underqualified inspectors and inefficient reporting lines between the IES Chief Directorate and provincial offices. While a matrix system has been proposed to tackle this last issue, it has not yet been implemented.

What broader themes can be deduced from this study? One of the themes raised in the literature review was the indifferent record of NPM in developing countries. Schick (1988) argued that NPM reforms are unsuitable for developing countries given that such countries were often characterised by informality rather than by bureaucratic rules and contracts. South Africa has gone further than almost all African countries in introducing NPM-inspired performance management. In recent years, performance management measures have been strengthened through the introduction of sharper indicators, greater verification of results and uniform reporting of goals achieved by departments in annual reports (Fernandez and Lee, 2016). Nonetheless, South Africa has also been afflicted by neo-patrimonial policies found in many African countries. The government has set up a judicial Commission to investigate state capture, corruption and fraud in the public sector to deal with the many allegations of patronage, nepotism and corruption. There is a curious mix of NPM policies and informally based neo-patrimonialism. In some cases, performance management was rigorously applied. In other departments, lip service was applied to performance management. There are elements of both tendencies in the DoL. A strong commitment to performance management co-exists with a lack of capacity and an uneven commitment to skills and efficiency. This resonates with Van Holdt's (2010) study of the public hospitals in South Africa which shows an ambivalent attitude towards skills. 
The second theme is that of ICT. It was pointed out that the ICT system failed to create a seamless electronic management system to enhance performance. The problems of ICT are not, however, confined to developing countries and there have been plenty of examples of ICT systems failing in developed countries too. Hood and Peters (2004) point to the often mistaken belief of policy makers that outsourced technology will modernise bureaucracies. There is one aspect of NPM-inspired contracting out that seems to affect developing countries more, namely the inability of poorly capacitated public services. to manage the contracts with external providers. This was the case with the DoL and it seems to give credence to Schick's argument that contract-based management is often beyond the reach of developing countries.

\section{NOTES}

1. Before 1995 there was separate labour legislation for the public and private sectors.

2. In 2019 the name of the Department was changed from the Department of Labour to the Department of Employment and Labour. The President of the country Cyril Ramaphosa stated that the change will demonstrate that government is serious about creating jobs (IOL News, New Labour and Employment Department to actively focus on jobs, 31 May 2019). Given this is a recent change and for the sake of continuity, the Department will be referred to as the Department of Labour.

3. NEDLAC is the vehicle by which government, labour, business and community organisations cooperate through problem-solving and negotiation, on economic, labour and development issues, and related challenges facing the country.

4. There are 32 government departments in South Africa which share the 12 outcomes. Some outcomes are performed by a number of government departments.

\section{REFERENCES}

Bird, S.M., Cox, D., Farewell, F.T., Goldstein, H., and Smith, P.C. (2005), 'Performance indicators, good, bad and ugly'. Journal of the Royal Statistical Society, 168 (1), $1-27$.

Brinkerhoff, D.W., and Brinkerhoff, J.F. (2015), 'Public sector management reform in developing countries: Perspectives beyond NPM orthodoxy', Public Administration and Development, 35, 222-37.

Cameron, R. (2009), 'New Public Management reforms in the South African public service', Journal of Public Administration, 44 4(1), 910-42.

Cameron, R. (2015), 'Performance management in the South African Department of Labour', African Journal of Public Affairs, 8(1), 1-18.

Christensen, T., and Lægreid, P. (2015), 'Performance and accountability - a theoretical discussion and an empirical assessment', Public Organization Review, 15 (2), 207-25.

DoL (2011), Strategic Plan: 2011-2016, Pretoria.

DoL (2013), Annual Performance Plan, 2013-2014, Pretoria.

DoL (2014), Annual Report, Pretoria.

DoL (2015a), Annual Performance Plan 2015-2016, Pretoria. 
DoL (2015b), Organisation Performance Management Policy, Pretoria.

DoL (2015c), Re Planning and Reporting Guidelines and Standard Operating Procedures, 2015/16, Pretoria.

DoL (2017), Revised Strategic Plan 2015-2020, Pretoria.

DoL (2018a), Annual Performance Plan 2017-2018, Pretoria.

DoL (2018b), Annual Report 2017-2018, Pretoria.

DoL (2019), Annual Performance Plan, 2019/2020, Pretoria.

Fernandez, S., and Lee, H. (2016), 'The transformation of the South African Public Service: Exploring the impact of racial and gender representation on organisational effectiveness', Journal of Modern African Studies, 54 (2), 91-116.

Hood, C. (1991), 'A public management for all seasons?' Public Administration, 69 (1), 3-19.

Hood, C. (2007), 'Public service management by numbers: Why does it vary? Where has it come from? What are the gaps and the puzzles?', Public Money \& Management, 27 (2), 95-102.

Hood C., and Peters, B.G. (2004), 'The middle aging of new public management: Into the age of paradox?', Journal of Public Administration Research and Theory, 14 (3): $267-82$.

Hughes, O. (2003), Public Management and Administration: An Introduction (3rd edn), Basingstoke and New York: Palgrave Macmillan.

ILO (2010), Technical Memorandum South Africa. Labour Administration and Inspection Programme, Geneva.

ILO (2011), Performance Management in the South African Department of Labour, Pretoria.

ILO (2015), An Analysis of Labour Administration in South Africa, Pretoria.

Larbi, A. (1999), The New Public Management Approach and Crisis States, UNRISD Discussion Paper No. 112, Geneva: United Nations Research Institute for Social Development.

Manning, N. (2001), 'The Legacy of the New Public Management in developing countries', International Review of Administrative Sciences, 67 (2), 297-312.

McCourt, W. (2013), Models of Public Service Reform. A Problem-Solving Approach, Policy Research Working Paper 6428, Washington, DC: World Bank.

McCourt, W., and Gulrajani, N. (2010), 'The future of development management: Introduction to the special issue', Public Administration and Development 30, $81-90$.

Miller, K. (2005), Public Sector Reform Governance in South Africa, Aldershot: Ashgate.

Minogue, M. (1998), 'Changing the state: Concepts and practice in the reform of the public sector', in Minogue, M., Polidano, C., and Hume, D. (eds), Beyond the New Public Management, Changing Ideas and Practices in Governance, Cheltenham, UK and Northampton, MA, USA: Edward Elgar, 17-37.

National Planning Commission (2012), National Development Plan 2030. Our Future - Make It Work, Pretoria.

National Treasury (2007), Framework for Managing Programme Performance Information, Pretoria: Treasury.

Olowu, D (2010), 'Civil service pay reforms in Africa', International Review of Administrative Sciences, 76 (4), 632-52.

Polidano, C. (1999), The New Public Management in Developing Countries, IDPM Public Policy and Management, Working Paper No. 13, Manchester: Institute for Developmental Policy and Management (IDPM), University of Manchester. 
Pollitt, C. (1993), Managerialism in the Public Services: Cuts or Cultural Changes in the 1990s? Oxford: Basil Blackwell.

Pollitt, C. (2003), 'Joined-Up government: A survey', Political Studies Review, 1, $34-49$.

Pollitt, C., and Bouckaert, G. (2011), Public Management Reform. A Comparative Analysis. New Public Management, Governance, and the Neo-Weberian State, Oxford: Oxford University Press.

Pritchett, L., Woolcock, M., and Andrews, M. (2012), Looking Like a State: Techniques of Persistent Failure in State Capability for Implementation, Working Paper 2012/63, Helsinki: UNU-WIDER.

Schick, A. (1998), 'Why most countries should not try New Zealand reforms', The World Bank Research Observer, 13 (1), 123-31.

Talbot, C. (2004), 'A radical departure? Executive agencies in Jamaica', in Pollitt, C. and Talbot, C. (eds), Unbundled Government. A Critical Analysis of the Global Trend to Agencies, Quangos and Contractualisation, London: Routledge, 297-315.

Talbot, C. (2005), 'Performance management', in Ferlie, E., Lynn, L. and Pollitt, C. (eds), The Oxford Handbook of Public Management, Oxford: Oxford University Press, 491-517.

The Presidency (2009), Improving Government Performance: Our Approach, Pretoria. Von Holdt, K. (2010), 'Nationalism, bureaucracy and the development state: The South African case', South African Review of Sociology, 41 (1), 4-27. 